УДК 342

\title{
ПРАВОМЕРНОСТЬ ОГРАНИЧЕНИЯ КОНТЕНТА С ПРИСУТСТВИЕМ НЕЦЕНЗУРНОЙ БРАНИ В СЕТИ ИНТЕРНЕТ
}

Тороп Сергей Сергеевич

студент

Научный руководитель: Суркова Ольга Егоровна

к.н.Д., доцент

ФГАОУ ВО «Самарский государственный экономический университет»

\begin{abstract}
Аннотация: В данной научной статье рассматривается правомерность ограничения контента с присутствием нецензурной брани в сети Интернет национальным законодательством Российской Федерации. Изучается отношение сложившегося мнения по отношению к существующему федеральному закону, регламентирующему ограничения неприемлемого контента в сети Интернет, а также контента, который содержит в себе нецензурную брань. Приводятся статистические данные, изучаются данные мониторинга социальных сетей. Осуществляется анализ введенных ограничений, изучается их цели, задачи, соответствие конституционности.
\end{abstract}

Ключевые слова: Интернет, нецензурная брань, цензура, конституционность, федеральный закон, международные нормы, ограничения.

\section{THE LEGALITY OF THE CONTENT OF THE CONTENT WITH THE PRESENCE OF FOUL LANGUAGE IN THE CITY OF THE INTERNET}

\section{Torop Sergey Sergeevich Surkova Olga Egorovna}

\begin{abstract}
This scientific article examines the legality of restricting content with the presence of obscene language in the city Internet by the national legislation of the Russian Federation. The article examines the relationship, the prevailing opinion in relation to the existing federal law regulating the restrictions of unacceptable content on the Internet, as well as content that contains obscene
\end{abstract}




\section{НАУКА, ОБЩЕСТВО, КУЛЬТУРА: ПРОБЛЕМЫ И ПЕРСПЕКТИВЫ ВЗАИМОДЕЙСТВИЯ В СОВРЕМЕННОМ МИРЕ}

language. Statistical data are provided, data from monitoring social networks are studied. The analysis of the introduced restrictions is carried out, their goals, objectives, compliance with the Constitutionality are studied.

Key words: Internet, foul language, censorship, constitutionality, federal law, international norms, restrictions.

30.12.2020 в Федеральный закон от 27.07.2006 №149-Ф3 «Об информации, информационных технологиях и защите информации» были внесены изменения согласно которым законодатель обязал владельцев сайтов, социальных сетей и иных информационных платформ сети Интернет не допускать распространение информации порочащей честь и достоинство граждан или отдельных категорий граждан по разным индивидуальным признакам, которые охраняются Конституций Российской Федерации. Кроме того, теперь владельцы Интернет-платформ обязаны осуществлять мониторинг с целью выявления и удаления материалов порнографического содержания с изображением несовершеннолетних, а также объявлений с призывами в адрес несовершеннолетних участвовать в порнографии. Законодательство устанавливает требование к удалению контента, где осуществляется информирование о производстве, способах изготовления запрещенных материалов, веществ и многое другое, установленное данной поправкой и иными федеральными законами. [Статья 1 / КонсультантПлюс [Электронный pecypc]. URL: http://www.consultant.ru/document/cons_doc_LAW_372700/3d0cac6 0971a511280cbba229d9b6329c07731f7/ (дата обращения: 30.03.2021).].

Необходимость внесения данных изменений обусловлена большим наличием нежелательного, незаконного, запрещенного российским законодательством контента в сети Интернет, который пагубно влияет на общественную нравственность, на развитие несовершеннолетних, на защиту их прав и законных интересови национальную безопасность. Данная проблема существует на протяжении длительного времени, с момента создания сети Интернет. Так с ноября 2018 по март 2019 года, в сети Интернет, а именно конкретно в социальной сети «Facebook» было выявлено 24,6 млн единиц контента сексуального характера. Буллинг и преследования составил цифру в размере 2,6 млн. Детская порнография и сексуальная эксплуатация детей - 5,4 млн. Контент, направленный на разжигания ненависти - 4 млн. Продажа наркотиков и оружия - 1560. Пропаганда терроризма - 6,4 млн. Пропаганда 


\section{НАУКА, ОБЩЕСТВО, КУЛЬТУРА: ПРОБЛЕМЫ И ПЕРСПЕКТИВЫ ВЗАИМОДЕЙСТВИЯ В СОВРЕМЕННОМ МИРЕ}

насилия - 33,6 млн. Граждане России жалуются в большом количестве на контент с призывами к самоубийствам, в эквиваленте 41 тысячи обращений с жалобой на такой контент. 111 тысяч жалоб, связаны с оборотом наркотиков. 260 тысяч - азартные игры. 42 тысячи - детская порнография. И это только данные об одной социальной сети, а такого контента в сети миллиарды. [Сколько в интернете агрессии и преступности? Что не так с методами борьбы с ними? - TACC [Электронный ресурс]. URL: https://tass.ru/obschestvo/6703517 (дата обращения: 30.03.2021).].

Поправки, направленные на защиту интересов, оправдывают себя, они необходимы при сегодняшних обстоятельствах и рисках национальной безопасности России. Однако, не все граждане России восприняли данные изменения как позитивное явление. Это обусловлено массовым тиражированием СМИ таких заголовков как «С 1 февраля в социальных сетях запретят ругаться матом», «В России решили запретить мат в социальных сетях», «Вступил в законную силу закон о мате» и другие аналогичные заголовки, которые выдает поисковая система «Google» [закон о мате - Поиск в Google [Электронный ресурс]. URL: https://www.google.com/search?q=\%d0\%b7 $\% \mathrm{~d} 0 \% \mathrm{~b} 0 \% \mathrm{~d} 0 \%$ ba\%d0\%be\%d0\%bd+\%d0\%be+\%d0\%bc\%d0\%b0\%d1\%82\%d0\%b5 \&aff=test123 (дата обращения: 30.03.2021).].

В связи с чем, сложилось мнение, что данный закон направлен на ограничение их конституционных прав и свобод, а именно ч. 1,4,5 ст. 29 Конституции Российской Федерации. [Статья 29 / КонсультантПлюс [Электронный pсypc]. URL: http://www.consultant.ru/document/cons_doc_LAW_ 28399/f703218d9357338507052de484404828b3da468e/ (дата обращения: 30.03.2021).].

Данная реакция общества на указанные заголовки, якобы устанавливающие цензуру, обусловлена тем, что пользователи сети активно используют мат как способ выражения своих эмоций и ограничение в этой области воспринимается, как ограничение свободы слова, свободы выражения своей мысли, цензуры. По данным социологов 10\% граждан России используют нецензурную лексику часто. $49 \%$ матерятся иногда, а $37 \%$ заявили, что практически никогда не используют бранные слова. 4\% затрудняются ответить. Таким образом у 59\% граждан России мат является неотъемлемой частью русской речи, конечно же в разном объеме, контексте и т.д. [Опрос: больше половины россиян используют в речи мат - BBC News Русская служба 


\section{НАУКА, ОБЩЕСТВО, КУЛЬТУРА: ПРОБЛЕМЫ И ПЕРСПЕКТИВЫ ВЗАИМОДЕЙСТВИЯ В СОВРЕМЕННОМ МИРЕ}

[Электроный рсурс]. URL: https://www.bbc.com/russian/russia/2015/02/150202_ru ssia_polls_swearing (дата обращения: 30.03.2021).].

В связи со сложившейся обстановкой, вокруг данных изменений, новшеств, в знак протеста 1 и 2 февраля 2021 года россияне в социальных сетях «ВКонтакте», «Однокласники», «Facebook», «Twitter», «Instagram» осуществили 646100 публикаций с использованием нецензурной брани. 3-4 февраля в этих же соцсетях было зафиксировано 426500 публикаций с использованием ненормативной лексики. И это только данные по указанным социальным сетям. [В соцсетях стало больше мата после его запрета: Технологии и медиа :: РБК [Электронный pecypc]. URL: https://www.rbc.ru/ technology_and_media/ 05/02/2021/601bd5dd9a79470b25b108a2 (дата обращения: 30.03.2021).].

Для разрешения данной проблемы необходимо провести анализ Конституции Российской Федерации и Федерального закона от 27.07.2006 №149-Ф3 «Об информации, информационных технологиях и защите информации», с изменениями от 30.12.2020 №530-ФЗ. Так, согласно п. ж ст. 10.6 указанного Ф3, владелец Интернет-платформы обязан мониторить, выявлять и удалять «информацию, выражающуюся в некорректной форме, которая оскорбляет человеческое достоинство и общественную нравственность, выражает явное неуважение к обществу, государству». Чтобы понять, что законодатель имеет в виду под «информацией, оскорбляющей человеческое достоинство и общественную нравственность», необходимо произвести анализ действующего законодательства. Так например из ч. 1 ст. 20.1 КоАП РФ следует, что хулиганством, помимо деяний, изложенных в диспозиции статьи, следует считать «нецензурную брань», ч. 3 ст. 20.1 КоАП устанавливает, что данные деяния, выраженные в нецензурной брани в «сети Интернет» также считаются хулиганскими и за это установлена административная ответственность. Также из ч. 1 ст. 20.1 КоАП РФ следует, что хулиганство это действия, оскорбляющие человеческое достоинство и общественную нравственность. Исходя из этого, п. ж ст. 10.6 Федерального закона от 27.07.2006 №149-Ф3, считает мат как «информацию, выражающуюся в неприличной форме, которая оскорбляет человеческое достоинство и общественную нравственность, проявляет явное неуважение к обществу, государству», как и следует из вышеуказанной статьи. [«Кодекс Российской Федерации об административных правонарушениях» (КОАП РФ) от 30.12.2001 N 195-Ф3 (последняя редакция) / КонсультантПлюс [Электронный ресурс]. 


\section{НАУКА, ОБЩЕСТВО, КУЛЬТУРА: ПРОБЛЕМЫ И ПЕРСПЕКТИВЫ ВЗАИМОДЕЙСТВИЯ В СОВРЕМЕННОМ МИРЕ}

URL: http://www.consultant.ru/document/cons_doc_LAW_34661/ (дата обращения: 30.03.2021).].

Из анализа конституционных норм следует, что согласно ч. 1 ст. 29 Конституции РФ «Каждому гарантируется свобода мысли и слова». Данное право неотчуждаемо и Федеральным законом от 27.07.2006 №149-Ф3 не установлен запрет на выражение мысли и слова. Указанный закон устанавливает обязанность владельцев Интернет-платформ удалять со своих социальных сетей мат и иной аморальный, запрещенный, незаконный контент. Данные действия никаким образом не ущемляют право граждан на свободу слова и мысли. Гражданин может размещать данный нецензурный контент и никто не может ему помешать в этом, но владелец платформы вправе удалить данный контент на правах владельца Интернет-сервиса, на котором был размещен данный контент, запрещенный указанным законом, то есть, например, мат - нецензурная брань. А ввиду поправок в указанный федеральный закон, владелец Интернет-сервиса теперь еще и обязан удалять данный нежелательный контент. Глобальных изменений, выраженных в изменениях, как принято сравнивать на до и после, не произошло. Владелец Интернет-сервиса и раньше мог удалить тот или иной нежелательный контент, а теперь обязан, независимо от его желания и отношения к данному контенту.

Также согласно ч. 4 ст. 29 Конституции РФ «каждый имеет право свободно искать, получать, передавать, производить и распространять информацию любым законным способом». Данное право также не нарушается данным федеральным законом, так как в данной норме содержатся следующая фраза «любым законным способом», а исходя из того, что данный порядок о реализации данного конституционного права определяется Федеральным законом от 27.07.2006 №149-Ф3, в котором теперь мат является «вне закона», «под запретом», тем самым искать, получать, передавать, производить и распространять информацию в виде мата незаконно, тем самым о нарушении конституционного права речи и быть не может.

И согласно ч. 5 ст. 29 Конституции РФ «Гарантируется свобода массовой информации. Цензура запрещается». Что касается, данной нормы необходимо обратится к ч. 3 ст. 55 Конституции РФ, согласно которой: «Права и свободы человека и гражданина могут быть ограничены федеральным законом только в той мере, в какой это необходимо в целях защиты основ конституционного строя, нравственности, здоровья, прав и законных интересов других лиц», 


\section{НАУКА, ОБЩЕСТВО, КУЛЬТУРА: ПРОБЛЕМЫ И ПЕРСПЕКТИВЫ ВЗАИМОДЕЙСТВИЯ В СОВРЕМЕННОМ МИРЕ}

исходя из этого как мы уже выше установили, что «мат» является информацией оскорбляющей человеческой достоинства и общественную нравственность, тем самым учитывая, что основанием ограничения прав и свобод является «защита нравственности», ограничение является обоснованным и законным.

Кроме того, Россией 30.03.1998 была ратифицирована «Европейская конвенция по правам человека». Исходя из ч. 2 ст. 10 указанной конвенции следует, что «Осуществление свобод, налагающее обязанности и ответственность, может быть сопряжено с определенными формальностями, условиями, ограничениями или санкциями, которые предусмотрены законом и необходимы в демократическом обществе в интересах национальной безопасности, нравственности, защиты репутации или прав других лиц и т.д.». То есть введенные ограничения в обсуждаемый закон являются законными в рамках как национального права, так и международного права. И нарушения Конституционных прав и свобод граждан России данные изменения в указанный выше закон за собой не несут. [«Европейская конвенция о защите прав человека и основных свобод [Электронный ресурc]. URL: https://www. coe.int/ru/web/compass/the-european-convention-on-human-rights-and-its-protocols (дата обращения: 30.03.2021).].

Анализируя вышеизложенное, можно прийти к выводу, что беспокойство граждан по поводу неправомерности, незаконности, неконституционности изменений в указанный закон напрасны. Паника среди населения вызванная искусственным путем в криминологии, именуемой как «моральная паника», то есть, когда средства массовой информации путем манипуляций транслируют населению информацию, подавая в таком виде в каком выгодно им, для подогревания интереса к их сюжету, тем самым делая рейтинги и магнетизируя контент за счет интересов населения. Данные действия следует считать, дискредитацией данного федерального закона, подменяя понятия законности и антиконституционности, вводя в заблуждения граждан, не обладающими достаточными знаниями в области права.

\section{Список литературы}

1. Статья 1 / КонсультантПлюс [Электронный ресурc]. URL: http://www. consultant.ru/document/cons_doc_LAW_372700/3d0cac60971a511280cbba229d9b6 329c07731f7/ (дата обращения: 30.03.2021). 
2. Сколько в интернете агрессии и преступности? Что не так с методами борьбы с ними? - TACС [Электронный ресурс]. URL: https://tass.ru/obschestvo/ 6703517 (дата обращения: 30.03.2021).

3. закон о мате - Поиск в Google [Электронный ресурс]. URL: https://www.google.com/search?q=\%d0\%b7\%d0\%b0\%d0\%ba\%d0\%be\%d0\%bd+\%d $0 \% \mathrm{be}+\% \mathrm{~d} 0 \% \mathrm{bc} \% \mathrm{~d} 0 \% \mathrm{~b} 0 \% \mathrm{~d} 1 \% 82 \% \mathrm{~d} 0 \% \mathrm{~b} 5 \& \mathrm{aff}=$ test 123 (дата обращения: 30.03.2021).

4. Статья 29 / КонсультантПлюс [Электронный ресурс]. URL: http://www.consultant.ru/document/cons_doc_LAW_28399/f703218d935733850705 2de484404828b3da468e/ (дата обращения: 30.03.2021).

5. Опрос: больше половины россиян используют в речи мат - BBC News Русская служба [Электронный ресурс]. URL: https://www.bbc.com/russian/ russia/2015/02/150202_russia_polls_swearing (дата обращения: 30.03.2021).

6. В соцсетях стало больше мата после его запрета: Технологии и медиа: РБК [Электронный pecypc]. URL: https://www.rbc.ru/technology_and_ media/05/02/2021/601bd5dd9a79470b25b108a2 (дата обращения: 30.03.2021).].

7. «Кодекс Российской Федерации об административных правонарушениях» (КОАП РФ) от 30.12.2001 N 195-Ф3 (последняя редакция) / КонсультантПлюс Электронный ресурс]. URL: http://www.consultant.ru/ document/cons_doc_LAW_34661/ (дата обращения: 30.03.2021).

8. «Европейская конвенция о защите прав человека и основных свобод [Электронный pecypc]. URL: https://www.coe.int/ru/web/compass/the-europeanconvention-on-human-rights-and-its-protocols (дата обращения: 30.03.2021).

(C) C.C. Тороп, 2021 